\title{
Numerical Taxonomy of Actinomadura and Related Actinomycetes
}

\author{
By M. GOODFELLOW, GRACE ALDERSON \\ Department of Microbiology, Medical School, The University, \\ Newcastle upon Tyne NE1 7RU \\ AND J. LACEY \\ Rothamsted Experimental Station, Harpenden AL5 2JQ, Hertfordshire
}

(Received 21 September 1978; revised 17 November 1978)

\begin{abstract}
One hundred and fifty-six Actinomadura strains, marker strains of related taxa, and related isolates from bagasse and fodder were the subject of numerical phenetic analyses using 90 unit characters. The data were examined using the simple matching $\left(S_{S M}\right)$, Jaccard $\left(S_{J}\right)$ and pattern $\left(D_{P}\right)$ coefficients and clustering was achieved using both single and average linkage algorithms. Cluster composition was not markedly affected either by the coefficient or clustering algorithms used or by test error, estimated at $4.5 \%$. Actinomadura dassonvillei, Actinomadura madurae and Streptomyces somaliensis formed good taxospecies, but the separation of Actinomadura pelletieri strains into two clusters by $S_{J}$ and $S_{S M}$ analysis requires further study. The single representatives of Actinomadura helvata, Actinomadura pusilla, Actinomadura roseoviolacea, Actinomadura spadix and Actinomadura verrucosospora seemed to form new centres of variation while Actinomadura citrea and Actinomadura malachitica showed much similarity with Actinomadura madurae. Most of the isolates from bagasse and fodder were recovered in two well-defined phena, provisionally labelled clusters 'A' and 'B' which showed little similarity to either Actinomadura or Nocardia strains. The effect of the different coefficients on the aggregation of clusters is discussed.
\end{abstract}

\section{INTRODUCTION}

The genus Actinomadura Lechevalier \& Lechevalier 1970 was proposed to accommodate so-called Nocardia species with walls containing meso-diaminopimelic acid but lacking arabinose and galactose (Becker et al., 1965). Initially, three species, Nocardia dassonvillei (Gordon \& Horan, 1968), Nocardia madurde and Nocardia pelletieri (Gordon, 1966), were transferred to Actinomadura, which was classified in the family Thermoactinomycetaceae. Later, the genus was transferred to the family Thermomonosporaceae because endospores were not produced (Cross \& Goodfellow, 1973). The separation of Actinomadura from Nocardia has subsequently been supported by numerical phenetic (Tsukamura, 1969; Goodfellow, 1971), DNA-DNA reassociation (Mordarski et al., 1977), phage typing (Prauser, 1976), chemical (Goodfellow \& Minnikin, 1978) and serological (Goodfellow et al., 1974) data. However, the 8th edition of Bergey's Manual of Determinative Bacterio$\log y$ (McClung, 1974) describes Actinomadura as a genus incertae sedis, thus perpetuating the unsettled taxonomic history of the species it contains (Lacey et al., 1978).

Further Actinomadura species have been recognized on the basis of morphology and wall chemotype (Lacey et al., 1978); consequently little is known of the relationships of these taxa to one another or to the three originally described species (Lechevalier \& Lechevalier, 1970). In a numerical taxonomic survey, however, Actinomadura dassonvillei strains were only loosely associated with clusters corresponding to Actinomadura madurae and Actinomadura pelletieri although all three species formed an aggregate taxon equivalent in rank to 
clusters equated with Nocardia, Oerskovia and Rhodococcus (Goodfellow, 1971). Actinomadura dassonvillei can be distinguished from the other two species on the basis of spore morphology (Williams et al., 1976), fatty acid composition (Agre et al., 1975), pigmentation (Lechevalier et al., 1971), absence of madurose (3-O-methyl-D-galactose; Lechevalier \& Gerber, 1970), menaquinone composition (Collins et al., 1977) and polar lipid composition (Minnikin et al., 1977). Meyer (1976) proposed the new genus Nocardiopsis for this species.

Classically, actinomadurae have been isolated from clinical material. Actinomadura madurae and $A$. pelletier $i$ are primary agents of actinomycete mycetoma in man. Although $A$. dassonvillei was first isolated from mouldy oat grain (Brocq-Rousseu, 1904), it can infect animals and man (Gordon \& Horan, 1968; Schaal, 1977). It also occurs in hay, cotton and soil (Lacey et al., 1978). Most newly described species have been isolated from soil (Nonomura \& Ohara, 1971; Lavrova et al., 1972) while others, classified provisionally as Actinomadura strains on the basis of their morphology (Lacey, 1971, 1978), were isolated from mouldy hay and barley grain. In a subsequent review (Lacey et al., 1978), however, the affinities of these isolates were considered to be uncertain.

In the present study, representatives of Actinomadura spp., marker cultures of Nocardia spp. and Streptomyces somaliensis, and 'Actinomadura' isolates from mouldy hay and fodder were compared using numerical phenetic methods in an attempt to clarify the intra- and supra-generic relationships of Actinomadura.

\section{METHODS}

Strains. The 156 test strains (Table 1) were maintained on glucose yeast extract agar (GYEA) at room temperature (Gordon \& Mihm, 1962).

Isolation of 'Actinomadura' strains. These strains were isolated from air, bagasse and fodder using a wind-tunnel technique (Lacey, 1971, 1974); the Anderson sampler was loaded with Petri dishes containing half-strength nutrient agar medium supplemented with $50 \mu \mathrm{g}$ actidione $\mathrm{ml}^{-1}$ (Gregory \& Lacey, 1963).

Collection of data. Each strain was examined for 90 unit characters (Tables 2 and 3). Media were inoculated from $\Theta Y E A$ cultures and incubated at $37^{\circ} \mathrm{C}$ for up to $21 \mathrm{~d}$, unless otherwise stated. A few of the 'Actinomadura' isolates (A53, A62, A66, A79, A81 and A89) that grew poorly, if at all, at $37^{\circ} \mathrm{C}$ were incubated at $30^{\circ} \mathrm{C}$. Growth tests were performed in divided polystyrene Replidishes (Sneath \& Stevens, 1967); antibiotic sensitivity, colony morphology and degradation tests were done in Petri dishes; and urease, allantoinase and lysozyme activity were examined in test-tubes. Most of the media and methods used have been described elsewhere (Goodfellow, 1971; Lacey \& Goodfellow, 1975); details of the remainder are given below.

Colonial characters. Colony morphology and pigmentation were observed on GYEA plates after 7 and $14 \mathrm{~d}$.

Biochemical and degradative tests. Cultures were examined using methods previously described (Goodfellow, 1971; Lacey \& Goodfellow, 1975), with most tests being read after $14 \mathrm{~d}$. However, gelatin, starch, DNA and RNA tests were read after $7 \mathrm{~d}$, guanine and cellulose degradation after $21 \mathrm{~d}$ and allantoin and urea tests weekly up to 4 weeks. Ribonucleases were detected in a basal medium $(20 \mathrm{~g}$ tryptone, $5 \mathrm{~g} \mathrm{NaCl}$ and $15 \mathrm{~g}$ agar in 11 distilled water; at $\mathrm{pH} 7 \cdot 3)$ supplemented with RNA (0.3\%, w/v) (Jeffries et al., 1957).

Testosterone degradation was tested by streaking a dense inoculum of each culture across a plate containing $0 \cdot 1 \%(\mathrm{w} / \mathrm{v})$ testosterone (BDH) in Gordon's (1967) basal medium, and looking for the disappearance of the insoluble testosterone underneath and around the growth.

Organic compounds as sole sources of carbon. Strains were examined for their ability to grow on 42 carbon sources (Tables 2 and 3; Goodfellow, 1971).

Antibiotic sensitivity studies. Eleven antimicrobial agents contained in filter paper discs (Tables 2 and 3) were tested for activity against the strains by the method of Goodfellow \& Orchard (1974). Resistance to lysozyme was determined after $28 \mathrm{~d}$ (Gordon, 1966).

Coding of data. Nearly all of the characters existed in one of two mutually exclusive states and were scored plus $(+)$ or minus $(-)$. Qualitative multistate characters, such as pigmentation and colony elevation, were scored plus $(+)$ for the character state shown and minus $(-)$ for the alternatives; quantitative multistate characters, for example, aerial hyphae production, were scored by the additive method (Sneath \& Sokal, 1974). Sensitivity to antimicrobial agents was scored plus (+). The $n \times t$ table contained data for 156 bacteria and 90 unit characters. The binary data were recorded on standard IBM punch cards.

Computer analysis. Data were examined using the Clustan 1A program (Wishart, 1968) on an IBM370/180 


\section{Table 1. Designation and source of strains assigned to clusters based on pattern differences}

\section{A. Major clusters}

(a) Strains assigned to cluster 1 (Actinomadura madurae)

*A138 Actinomadura citrea, G. F. Gause, Institute of New Antibiotics, Bolshaia Pirogovskaia 11, Moscow U.S.S.R., INA 1849

A22 Actinomadura madurae, M. Mariat, Institut Pasteur, Paris, France, 725

A25 A. madurae, M. Mariat, 393

A30 A. madurae, M. Mariat, 703; mycetoma, Mexico

A31 A. madurae, M. Mariat, 363; madura foot, Tunis

A32 A. madurae, M. Mariat, 364; madura foot

$\dagger^{\mathrm{a} *} \mathrm{~A} 113$ A. madurae, ATCC 19425

A124 A. madurae, H. Prauser, Zentralinstitut für Mikrobiologie und Experimentelle Therapie, Jena, DDR, IMET 7144; H. A. Lechevalier; R. E. Gordon, 1136; soil

${ }^{\mathrm{b}} \mathrm{A} 125$ A. madurae, H. Prauser, IMET 7145; H. A. Lechevalier, Sal 1

A126 A. madurae, H. Prauser, IMET 7146; H. A. Lechevalier, 1091

A133 A. madurae, M. A. Gordon, Department of Health, Albany, New York, U.S.A., 291A

*A139 Actinomadura malachitica, G. F. Gause, INA 1920

*A4 Actinomadura verricosospora, H. Nonomura, Faculty of Engineering, Yamanashi University, Kofu, Japan, A184

A74 'Actinomadura'sp., J. Lacey, A270; hay

A107 'Actinomadura' sp., J. Lacey, A888; air sample, barley silo

2*A16 Nocardia madurae, NCTC 5654; J. T. Duncan in 1938; madura foot

A17 N. madurae, NCTC 1070; J. T. Duncan in 1934; madura foot

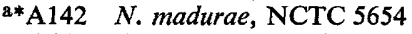

A11 Streptomyces madurae, C. Philpot, London School of Hygiene and Tropical Medicine, 393

A12 S. madurae, C. Philpot, 373

A38 S. madurae, CBS 331.54

A41 S. madurae, CBS 134.65

A43 S. madurae, CBS 254.58

(b) Strains assigned to cluster 2 (Actinomadura dassonvillei)

A114 Actinomadura dassonvillei, laboratory strain

c*A118 A. dassonvillei, H. Prauser; R. E. Gorden, IMRU 509

A119 A. dassonvillei, H. Prauser; R. E. Gordon, IMRU 714

dA120 A. dassonvillei, H. Prauser; R. E. Gordon, IMRU 1250

A121 A. dassonvillei, H. Prauser, IMET 9563; J. Meyer, 828.52; soil, Beirut, Lebanon

A129 A. dassonvillei, M. A. Gordon, 289G

A49 'Actinomadura' sp., J. Lacey, A286; barley grain

${ }^{\mathrm{c} * A 14}$ Nocardia dassonvillei, NCTC 10488; R. E. Gordon, IMRU 509

dA15 N. dassonvillei, NCTC 10489; R. E. Gordon, IMRU 1250; erosive plantar disease

A92 N. dassonvillei, W. A. Causey, Center for Disease Control, Atlanta, Ga., U.S.A., CDC W2536; drainage from hip

A93 N. dassonvillei, W. A. Causey, CDC N249; mycetoma, Colorado

A95 N. dassonvillei, W. A. Causey, CDC N2491; source unknown

A112 N. dassonvillei, W. A. Causey, CDC N291; cow

${ }^{\mathrm{c} A 141}$ N. dassonvillei, NCTC 10488

A132

A23

${ }^{\mathrm{e}} \mathrm{A} 24$

A33

A35

A36

A115

A128

A130

A131

f*A19

${ }^{\mathrm{g}} \mathrm{A} 20$

A21

A96

A97

bA123

f*A143

g N49

${ }^{\mathrm{h}} \mathrm{A} 100$

A7

A8 (c) Strains assigned to cluster 3 (Actinomadura pelletieri)
madurae, M. A. Gordon; H. M. Cameron, Nairobi, Kenya

Actinomadura madurae, M. A. Gordon; H. M. Cameron
Actinomadura pelletieri, M. Mariat, 374; Dakar, 1957

A. pelletieri, M. Mariat, 385

A. pelletieri, M. Mariat, 326

A. pelletieri, M. Mariat, 308

A. pelletieri, M. Mariat, 381

A. pelletieri, laboratory strain

A. pelletieri, laboratory strain

A. pelletieri, M. A. Gordon, $295 ;$ N. F. Conant

A. pelletieri, M. A. Gordon; H. M. Cameron, Nairobi, Kenya

Nocardia pelletieri, NCTC 4162; J. T. Duncan in 1933; E. C. Smith in 1928; mycetoma of arm

N. pelletieri, NCTC 9999; R. E. Gordon, 513 in 1957; P. Thibault in 1923

N. pelletieri, NCTC 10000 ; R. E. Gordon 687 in 1957; L. Ajello

N. pelletieri, W. A. Causey, CDC N242; Dr Anwar, Pakistan; mycetoma

N. pelletieri, W. A. Causey, CDC N86; N. F. Conant, 989

N. pelletieri, H. Prauser, IMET 7141 ; V. D. Kuznetsov, RIA 476

N. pelletieri, NCTC 4162

N. pelletieri, R. E. Gordon, Rutgers University, New Brunswick, U.S.A., 513

Nocardia (Proactinomyces) pelletieri, V. D. Kuznetsov, Research Institute for Antibiotics, Moscow, U.S.S.R., RIA 476

Streptomyces pelletieri, C. Philpot

S. pelletieri, C. Philpot, 3885 
A9 S. pelletieri, C. Philpot, 368

\section{Table 1 (cont.)}

A10 S. pelletieri, C. Philpot, 1065; E. C. Smith in 1929; arm of patient

A13 S. pelletieri, C. Philpot, $388 \mathrm{H}$

A37 S. pelletieri, CBS 708.70

A39 S. pelletieri, CBS 436.57

A42 S. pelletieri, CBS 294.64

A116 S. pelletieri, D. Frey, Institute of Medical Research, Crow's Nest, N.S.W., Australia, RNSH 203

eA117 S. pelletieri, D. Frey, RNSH 2022; Dr Segretain, IP 385

A122 S. pelletieri, H. Prauser, IMET 9592

N281 S. pelletieri, I. G. Murray, London School of Hygiene and Tropical Medicine, 1065

(d) Strains assigned to cluster 4 (Streptomyces somaliensis)

A18 Nocardia pelletieri, NCTC 3026; J. T. Duncan in 1929; mycetoma

A26 Streptomyces somaliensis, M. Mariat, 395; Fort Lamy, Chad

A27 S. somaliensis, M. Mariat, 702; Mexico

A28 S. somaliensis, M. Mariat, 313

A29 S. somaliensis, M. Mariat, 314

A34 S. somaliensis, M. Mariat, 383

N20 S. somaliensis, NCTC 3236

(e) Strains assigned to cluster 5 (cluster 'B')

A44 'Actinomadura' sp., J. Lacey, A1248; hay

A45 'Actinomadura' sp., J. Lacey, A640; hay

A46 'Actinomadura' sp., J. Lacey, A336; hay

A53 'Actinomadura' sp., J. Lacey, A670; barley

A62 'Actinomadura' sp., J. Lacey, A66; straw

A63 'Actinomadura' sp., J. Lacey, A1276

A66 'Actinomadura' sp., J. Lacey, A694; straw

A71 'Actinomadura' sp., J. Lacey, A548; barley

A79 'Actinomadura' sp., J. Lacey, A1247; hay

A81 'Actinomadura' sp., J. Lacey, A637; barley

A85 'Actinomadura' sp., J. Lacey, A333; hay

A86 'Actinomadura' sp., J. Lacey, A320; barley

A89 'Actinomadura' sp., J. Lacey, A674; barley

N263 Nocardia madurae-type, T. Cross, Bradford University, CUB410; J. Lacey, stored hay

$(f)$ Strains assigned to cluster 6 (cluster 'A')

A47 'Actinomadura' sp., J. Lacey, A676; bagasse

A48 'Actinomadura' sp., J. Lacey, A678; barley

A51 'Actinomadura' sp., J. Lacey, A337; oats

A54 'Actinomadura' sp., J. Lacey, A735; hay

A55 'Actinomadura' sp., J. Lacey, A428; barley

A64 'Actinomadura' sp., J. Lacey, A826; hay

A67 'Actinomadura' sp., J. Lacey, A491; barley

A68 'Actinomadura' sp., J. Lacey, A302; straw

A69 'Actinomadura' sp., J. Lacey, A307; barley

A70 'Actinomadura' sp., J. Lacey, A305; barley

A72 'Actinomadura' sp., J. Lacey, A410; barley

A73 'Actinomadura' sp., J. Lacey, A318; hay

A75 'Actinomadura' sp., J. Lacey, A673; barley

A77 'Actinomadura' sp., J. Lacey, A232; bagasse

${ }^{\mathrm{b}} \mathrm{A} 80$ 'Actinomadura' sp., J. Lacey, A443; H. A. Lechevalier, Sal 1

A83 'Actinomadura' sp., J. Lacey, A581; barley

A84 'Actinomadura' sp., J. Lacey, A470; barley

A87 'Actinomadura' sp., J. Lacey, A1016; hay

A88 'Actinomadura' sp., J. Lacey, A824; bagasse

A90 'Actinomadura' sp., J. Lacey, A272; straw

A91 'Actinomadura' sp., J. Lacey, A620; hay

A104 'Actinomadura' sp., J. Lacey, A232; bagasse

A106 'Actinomadura' sp., J. Lacey, A630; air sample, barley silo

B. Minor clusters

(g) Strains assigned to cluster 7 (Actinomadura roseoviolacea)

${ }^{1 * A 2}$ Actinomadura roseoviolacea, $\mathrm{H}$. Nonomura, A-5; soil

i*A140 A, roseoviolacea, H. Nonomura, A-5; soil

(h) Strains assigned to cluster 8

A108 'Actinomadura'sp., J. Lacey, A1273; hay

A109 'Actinomadura' sp., J. Lacey, A1295; hay 


\section{Table 1 (cont.)}

(i) Strains assigned to cluster 9 (Rhodococcus sp.)

A135 Nocardia madurae, Czechoslovak Collection of Microorganisms, J. E. Purkyne University, Brno, Czechoslovakia, CCM 5509

A136 N. madurae, CCM 5510

( $j$ ) Strains assigned to cluster 10 (Streptomyces $\mathrm{sp}$.)

N205 Nocardia gibsonii, ATCC 6852, NCTC 4575; A. G. Gibson

N206 Nocardia rangoonensis, ATCC 6860, NCTC 1678; pulmonary streptothrichosis

(k) Strains assigned to cluster 11 (Nocardia carnea)

${ }^{\mathrm{j}} \mathrm{N} 675$ Nocardia carnea, R. E. Gordon, ATCC 6847

iN676 N. carnea, R. E. Gordon, 3419, ATCC 6847

(l) Strains assigned to cluster 12 (Nocardia vaccinii)

*N537 Nocardia salmonicida, T. G. Pridham, NRRL, Peoria, U.S.A.

${ }^{\mathrm{k}}$ 681 Nocardia vaccinii, R. E. Gordon, 3500, ATCC 11092; N. R. Smith, BG19; stem galls, blueberry

${ }^{k}$ N682 N. vaccinii, R. E. Gordon, ATCC 11092

(m) Strains assigned to cluster 13 (Nocardia transvalensis)

${ }^{1}$ N679 Nocardia transvalensis, R. E. Gordon, 3426, NCTC 2392

${ }^{1}$ N680 N. transvalensis, R. E. Gordon, NCTC 2392

\section{Clusters containing single strains}

*A5 Actinomadura helvata, H. Nonomura, A-105; soil

A6 Actinomadura madurae, C. Philpot, 391

A127 A. madurae, H. Prauser, IMET 9562; soil, Japan

* A3 Actinomadura pusilla, H. Nonomura, A-118

*A1 Actinomadura spadix, H. Nonomura, A-116

A57 'Actinomadura' sp., J. Lacey, A879; coffee beans

A61 'Actinomadura' sp., J. Lacey, A893; bagasse

A76 'Actinomadura' sp., J. Lacey, A440; air

A82 'Actinomadura' sp., J. Lacey, A429; barley

N609 Micropolyspora caesia, J. Lacey, A1194

*N673 Nocardia aerocolonigenes, R. E. Gordon, ISP 5034

*N317 Nocardia asteroides, ATCC 19247; R. E. Gordon, 727

*N318 Nocardia brasiliensis, ATCC 19296; R. E. Gordon, 845

N215 Nocardia formica, J. E. Thiemann, Lepetit SpA, Milan, Italy, S542

N614 Nocardia fukuyae, S. Suzuki, Rikagaku, Kenkyusho, Wako-Shi, Saitano, Japan, 11/41

N68 Nocardia gardneri, Institute of Applied Microbiology, University of Tokyo, Tokyo, IAM0105

N531 Nocardia italica, CBS 609.67

N323 Nocardia keratolytica, ATCC 12484

A94 Nocardia madurae, W. A. Causey, CDC N273; Dr Londero, Brazil; burn eschar

A110 N. madurae, W. A. Causey, CDC N248; sputum

A111 N. madurae, W. A. Causey, CDC N272

A137 N. madurae, laboratory strain, K657

N319 Nocardia saturnea, ATCC 15778; P. Hirsch, 99; compost

A98 Nocardia (Proactinomyces) gardneri, V. D. Kuznetsov, RIA 634

A103 Nocardia (Proactinomyces) madurae, V. D. Kuznetsov, 452

A102 Nocardia (Proactinomyces) polychromogenes, V. D. Kuznetsov, RIA 675

A99 Nocardia (Proactinomyces) tenuis, V. D. Kuznetsov, RIA 638

N412 Streptosporangium sp., laboratory strain

N497 Streptosporangium sp., laboratory strain

* Type strains.

$\dagger$ Superior letters preceding laboratory numbers indicate triplicate $(\mathrm{a}, \mathrm{c})$ or duplicate $(\mathrm{b}, \mathrm{d}$ to $\mathrm{l})$ cultures.

computer using both the simple matching coefficient $\left(S_{S_{M}}\right.$; Sokal \& Michener, 1958), which includes both positive and negative matches, and the Jaccard coefficient $\left(S_{J}\right.$; Sneath, 1957) which includes positive matches only. Clustering was achieved using both single linkage and unweighted average linkage (UPGMA) algorithms (Sneath \& Sokal, 1974). Vigour and pattern statistics were also calculated (Wishart, 1968) and a sorted shaded diagram was prepared from the product of the pattern coefficient $\left(D_{P}\right)$, UPGMA analysis.

Analysis for mycolic acids. Three 'Actinomadura' cultures (A46, A84, A88) and two cultures received as Nocardia madurae (A135, A136) were examined for mycolic acids using the medium and methods described by Minnikin et al. (1975). 


\section{RESULTS}

\section{Clustering of the strains using the $D_{P}$ coefficient with the UPGMA algorithm}

The percentage dissimilarity $\left(D_{T}\right)$ between strains can be divided into vigour $\left(D_{V}\right)$ and pattern $\left(D_{P}\right)$ components (Sneath, 1968). $D_{V}$ expresses differences in total metabolic activity between strains, as measured by numbers of positive reactions, while $D_{P}$ takes account of which tests give positive results, allowing for differences in growth rates, periods of incubation and similar factors which normally distort similarity values. Since the test strains varied widely in rates of growth, classification based on the pattern coefficient, UPGMA analysis is described in detail.

Of the 156 test cultures, 137 were recovered in six major and seven minor clusters (Fig. 1). All clusters were distinct and homogeneous and were named, where possible, after type or authentic named strains found within them (Table 1). The properties of the major and minor clusters are given in Tables 2 and 3, respectively.

Most of the 23 strains in cluster 1 were isolated from clinical sources and identified as Actinomadura (or Nocardia or Streptomyces) madurae (Table 1). All three cultures of the type strain of $A$. madurae (A16, A113, A142) were recovered near the centre of this cluster but duplicate cultures of another strain, A125 and A80, were found, respectively, in clusters 1 and 6 (Table 1). Cluster 1 also included two isolates (A74, A107) from hay and barley, respectively, and the type cultures of Actinomadura malachitica (A139), Actinomadura citrea (A138) and Actinomadura verrucosospora (A4). It may be significant that these three showed a greater similarity to one another than to other strains in the cluster. Most of the remaining cultures received as $A$. (or $N$.) madurae (A6, A94, A110, A111, A127, A137) showed little similarity to cultures in clusters 1 or 6 or to one another, but two (A135, A136) formed cluster 9. The two strains in this cluster produced red colonies, a primary mycelium that soon fragmented into irregular elements, contained mycolic acids, grew on a wide range of carbon sources and were sensitive to lysozyme (Table 3). They thus resemble species of Rhodococcus (Goodfellow \& Alderson, 1977) and have probably been misidentified.

Cluster 2 contained 14 isolates from fodder, soil and clinical material and included duplicates of the type strain of Actinomadura (or Nocardia) dassonvillei (A14, A118). All but one of the isolates were received as $A$. (or $N$.) dassonvillei, the exception (A49) being labelled 'Actinomadura'sp.

The 31 strains forming the largest cluster, cluster 3, showed some heterogeneity although all were received as Actinomadura (or Nocardia or Streptomyces) pelletieri (Fig. 1), with one exception (A132) labelled $A$. madurae. Duplicates of the type culture of $A$. (or $N$.) pelletier (A19, A143) were both found in cluster 3. The cluster was distinct from cluster 4 which contained six strains of Streptomyces somaliensis and one evidently misidentified as $N$. pelletieri (A18).

Most isolates from grain and fodder were recovered in clusters 5 and 6, labelled clusters ' $B$ ' and 'A', respectively. Cluster 6 contained 23 isolates. Cluster 5 contained 14, one of which (N263) had previously been recovered by Goodfellow (1971) within subgroup A of his $N$. madurae group. Other 'Actinomadura' isolates were either recovered in cluster 8 (A108, A109) or as single strains (A57, A61, A76, A82). Cluster 7 contained only the duplicate cultures of Actinomadura roseoviolacea (A2, A140). The type cultures of Actinomadura helvata (A5), Actinomadura pusilla (A3) and Actinomadura spadix (A1) were not recovered in any of the defined clusters although the last was similar to A. roseoviolacea strains.

Marker cultures of Nocardia, Micropolyspora and Streptosporangium showed little similarity to the Actinomadura cultures, to the bagasse and fodder isolates or to one another (Fig. 1). Cluster 10 was quite distinct and contained strains received as Nocardia gibsonii (N205) and Nocardia rangoonensis (N206). The walls of both species contain LL-diaminopimelic acid and lack characteristic sugars (G. H. Bowden, personal communication) so 


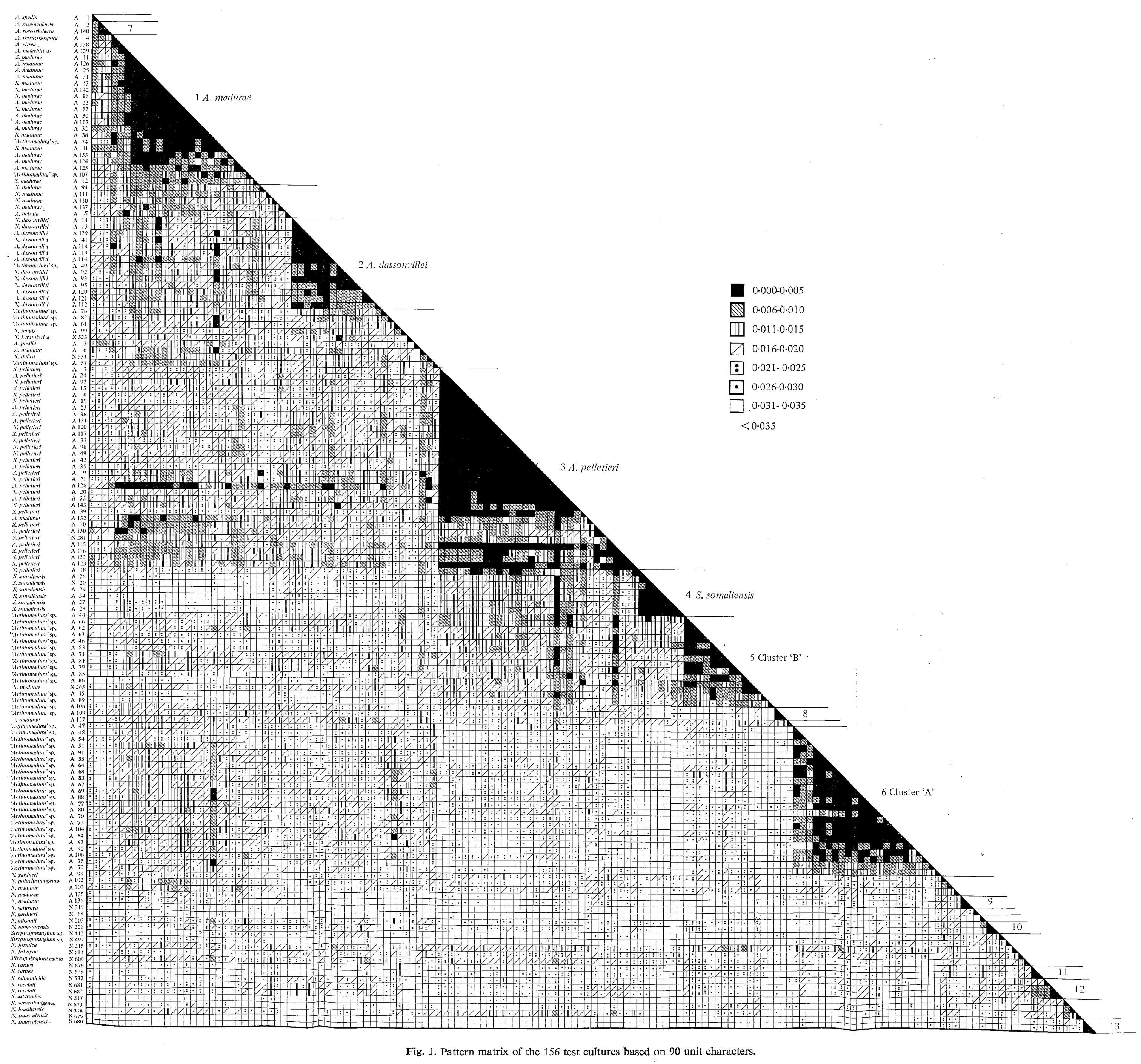


that their classification in the genus Streptomyces seems appropriate. Clusters 11 and 13 contained duplicate cultures of Nocardia carnea (N675, N676) and $N$. transvalensis (N679, N680), respectively. Cluster 12 included the duplicate cultures of $N$. vaccinii (N681, N682) with $N$. salmonicida (N537) loosely attached.

\section{Clustering of the strains using the $S_{S M}$ and $S_{J}$ coefficients with the UPGMA algorithm}

Cluster composition was only marginally affected when the $S_{J}$ and $S_{S M}$ coefficients were used with the UPGMA algorithm but the clusters were arranged differently (Figs 2 and 3). In each analysis, cluster 'B' and the $S$. somaliensis phenon were recovered in their entirety, as were the minor clusters with the exception of cluster 12 from which $N$. salmonicida (N537) was excluded.

Both the $S_{J}$ and $S_{S M}$ analyses modified cluster 1 ( $A$. madurae) by excluding $A$. verrucosospora A4 and the isolates A74 and A107. These three cultures remained differentiated from all of the defined clusters. $S_{J}$ analysis also separated $A$. madurae A132 from cluster 3 ( $A$. pelletieri) and A80, the duplicate of $\mathrm{A} 125$, from cluster 6 (cluster 'B'). $S_{S M}$ analysis grouped A132 with cluster 1 (A. madurae) and separated A80 from cluster 6 . It also removed five isolates (A10, A116, A122, A130, N281), which formed a loose subcluster by $D_{P}$ analysis, from cluster 3 to form a new cluster, 14 (Fig. 2).

Major clusters were recovered in two aggregates by $S_{S M}$ analysis (Fig. 2). One contained clusters 1 (A. madurae), 2 (A. dassonvillei), 6 (cluster 'A'), and 14 (A. pelletieri); the other included clusters 3 ( $A$. pelletieri), 4 ( $S$. somaliensis) and 5 (cluster 'B'). The first of these aggregates was also recovered by $S_{J}$ analysis, but with this coefficient clusters 3,4 and 5 showed little similarity to one another or to any other major cluster (Fig. 3). In the corresponding $D_{P}$ analysis, two aggregates were formed; the first contained $A$.dassonvillei and $A$. madurae, the second $A$. pelletieri, $S$. somaliensis and cluster 'B'. Cluster 'A' shared little similarity with either (Fig. 1). Only $A$. dassonvillei and $A$. madurae were consistently recovered in the same aggregate of clusters, but even they were only loosely associated in the $S_{J}$ analysis.

Clustering of the strains using the $S_{S M}$ and $S_{J}$ coefficients with the single linkage algorithm

The classifications obtained with the single linkage clustering method were almost the same as those formed in the UPGMA analyses. However, cluster 14 was recovered in both the $S_{J}$ and $S_{S M}$ analyses, while in the $S_{S M}$ analysis the $A$. pelletieri and $S$. somaliensis clusters formed two subgroups within a common cluster. Also strains A74 and A107 were recovered in cluster 6 (cluster 'A'); otherwise, cluster composition was not affected.

\section{Reproducibility of results}

Inclusion of duplicate and triplicate strains (Table 1) in the analysis enabled experimental test error to be estimated. The probability $(p)$ of an erroneous result averaged $4.5 \%$, equal to an observed $S_{S M}$ value of about $91 \%$ between duplicate cultures.

\section{Characters useful for the separation of Actinomadura species and allied taxa}

Characters potentially useful for the differentiation of Actinomadura species and related taxa are shown in Table 4.

\section{Analysis for mycolic acids}

Mycolic acids were detected in two cultures received as Nocardia madurae (A135, A136) but not in the representatives of clusters 'A' (A84, A88) and 'B' (A46). 
Table 2. Percentage frequencies of positive characters found in the major clusters

Cluster no.

No. of strains

Colonial characters:

Aerial hyphae sparse

Aerial hyphae moderate

Aerial hyphae abundant

Spines/tufts formed

Margin filamentous

Margin deeply filamentous

Elevation convex

Elevation crateriform

Elevation flat/raised

Elevation irregular

Colonies cream/white

Colonies pink/orange

Colonies red/maroon

Degradation of:

$\begin{array}{lr}\text { Adenine } & \\ \text { Aesculin } & 100 \\ \text { Casein } & 100 \\ \text { Chitin } & 70 \\ \text { DNA } & 100 \\ \text { Elastin } & 100 \\ \text { Gelatin } & \\ \text { Guanine } & 100 \\ \text { Hypoxanthine } & 100 \\ \text { Keratin } & 96 \\ \text { RNA } & 65 \\ \text { Starch } & 96 \\ \text { Testosterone } & 100 \\ \text { Tyrosine } & 9 \\ \text { Urea } & 9 \\ \text { Xanthine } & \end{array}$

Growth on sole carbon source $(1 \%$ w/v):

Adonitol
D-Arabinose
L-Arabinose
Amygdalin
Arbutin
Cellobiose
Dextrin
Dulcitol
Erythritol
Ethanol
Fructose
Galactose
Glycerol
Glycogen
Inositol
Inulin
Lactose
Maltose
Mannitol
Mannose
Melibiose
$\alpha$-Methyl-D-glucoside

1

23
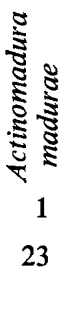

26
18

13
4

88

9
26

26
22

4

62

79

4
13

9
100

100

9
70

100

100

4
100

100

96
65

96

100

9

2

14

86

86

72

57

100

79

7

7

29

50

86

7
0

86

100

100

43

100

100

100

93

100

100

100

93

7
100
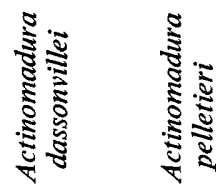

0
100

$96 \quad 22$

9
100

100

0
96

96
100

100
0

26

66

100

88

100

100
88

44

4

9

100

100

88

9

9

31

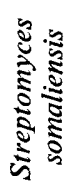

4

7

72

$\begin{array}{rrrr}30 & 72 & 36 & 79 \\ 3 & 57 & 29 & 75 \\ 0 & 29 & 0 & 44 \\ 3 & 43 & 7 & 9 \\ 68 & 100 & 86 & 96 \\ 0 & 72 & 0 & 26 \\ 19 & 0 & 7 & 9 \\ 10 & 100 & 22 & 35 \\ 0 & 0 & 0 & 4 \\ 71 & 14 & 86 & 62 \\ 23 & 86 & 86 & 88 \\ 7 & 0 & 0 & 9 \\ 68 & 14 & 0 & 0\end{array}$

$\begin{array}{rrrr}0 & 0 & 29 & 88 \\ 3 & 0 & 57 & 100 \\ 100 & 100 & 100 & 9 \\ 74 & 0 & 7 & 84 \\ 16 & 100 & 29 & 66 \\ 100 & 100 & 72 & 0 \\ 100 & 100 & 100 & 91 \\ 0 & 0 & 0 & 100 \\ 90 & 0 & 93 & 100 \\ 100 & 100 & 100 & 0 \\ 7 & 100 & 93 & 100 \\ 0 & 0 & 100 & 95 \\ 13 & 72 & 7 & 100 \\ 100 & 100 & 93 & 100 \\ 0 & 0 & 0 & 0 \\ 0 & 0 & 86 & 91\end{array}$

$\begin{array}{rrrr}3 & 0 & 86 & 100 \\ 0 & 0 & 29 & 88 \\ 13 & 0 & 7 & 100 \\ 0 & 0 & 0 & 0 \\ 0 & 0 & 7 & 9 \\ 16 & 0 & 22 & 88 \\ 19 & 0 & 7 & 100 \\ 0 & 0 & 7 & 0 \\ 0 & 0 & 86 & 100 \\ 3 & 0 & 29 & 96 \\ 16 & 0 & 14 & 100 \\ 16 & 0 & 93 & 100 \\ 19 & 0 & 100 & 100 \\ 19 & 0 & 7 & 96 \\ 0 & 0 & 0 & 96 \\ 0 & 0 & 0 & 13 \\ 0 & 0 & 14 & 9 \\ 68 & 72 & 7 & 100 \\ 19 & 0 & 100 & 96 \\ 3 & 0 & 50 & 100 \\ 0 & 0 & 0 & 70 \\ 0 & 0 & 22 & 18\end{array}$

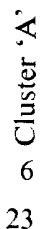

23

79

9

26

35

62

88
9

0

100

0

88

00 00

96

100

00

96

3

00

96

70 
Table 2 (cont.)
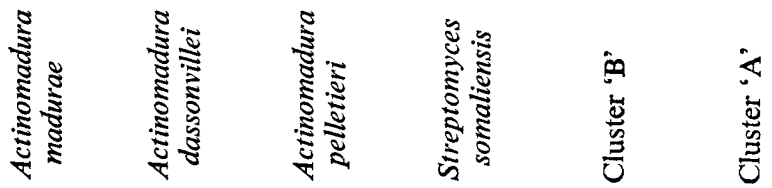

$\beta$-Methyl-D-glucoside
Raffinose
Rhamnose
Salicin
Sorbitol
Starch
Sucrose
Trehalose
Xylose

$22 \quad 100$

Growth on sole carbon source $(0.1 \%, w / v)$ :

Glucosamine

$m$-Hydroxybenzoic acid

$\begin{array}{rr}57 & 29 \\ 4 & 0 \\ 62 & 43 \\ 4 & 7 \\ 91 & 93 \\ 22 & 72 \\ 65 & 72 \\ 0 & 0\end{array}$

\section{0}

29

0

Sodium acetate

Sodium adipate

Sodium butyrate

Sodium octanoate

Sodium propionate

Sodium tartrate

$\begin{array}{rrrr}13 & 0 & 7 & 91 \\ 45 & 0 & 0 & 57 \\ 23 & 0 & 29 & 96 \\ 0 & 0 & 7 & 57 \\ 90 & 14 & 93 & 91 \\ 3 & 0 & 29 & 9 \\ 42 & 0 & 93 & 44 \\ 0 & 0 & 7 & 4\end{array}$

Resistance to:*

Demethylchlortetracycline (500)

Cephaloridine (100)

Gentamicin (100)

Lincomycin (100)

Neomycin (50)

Oleandomycin (100)

Penicillin (10 i.u.)

Rifampicin (50)

Streptomycin (100)

Tobramycin (50)

Vancomycin (50)

$\begin{array}{rrr}40 & 29 & 36 \\ 0 & 7 & 19 \\ 35 & 100 & 87 \\ 0 & 0 & 10 \\ 88 & 93 & 48 \\ 0 & 0 & 0 \\ 9 & 0 & 90 \\ 0 & 64 & 0 \\ 65 & 43 & 19 \\ 79 & 100 & 58 \\ 31 & 43 & 32\end{array}$

$\begin{array}{rrr}100 & 100 & 57 \\ 86 & 36 & 26 \\ 100 & 100 & 70 \\ 86 & 57 & 4 \\ 100 & 93 & 4 \\ 43 & 64 & 0 \\ 100 & 86 & 88 \\ 86 & 93 & 31 \\ 86 & 86 & 75 \\ 100 & 100 & 9 \\ 86 & 100 & 79\end{array}$

* Filter paper discs were soaked in antimicrobial agent at the concentrations $\left(\mu \mathrm{g} \mathrm{ml}^{-1}\right)$ given in parentheses; for penicillin, Oxoid discs were used.

No strains degraded xylan, produced allantoinases or brown colonies, were resistant to lysozyme or were able to use melezitose $(1 \%, \mathrm{w} / \mathrm{v})$ or testosterone $(0.1 \%, \mathrm{w} / \mathrm{v})$ as sole carbon sources. All strains degraded Tweens 20,40, 60 and 80 and used glucose $(1 \%, w / v)$ as a sole carbon source.

\section{DISCUSSION}

The numerical analyses confirm the sharp separation of Actinomadura and Nocardia (Tsukamura, 1969; Goodfellow, 1971). They also show that A. dassonvillei, A. madurae, $S$. somaliensis and clusters ' $\mathrm{A}$ ' and 'B' form good taxospecies, distinguishable by many characters (Table 4). However, the separation of $A$. pelletieri strains into two clusters by $S_{J}$ and $S_{S M}$ analyses requires further study. The affinities of representatives of new Actinomadura species are still unclear, although $A$. helvata, $A$. pusilla, $A$. roseoviolacea, $A$. spadix and $A$. verrucosospora (Nonomura \& Ohara, 1971) may form new centres of variation. However, A. citrea and A. malachitica (Lavrova et al., 1972) show some similarity with $A$. verrucosospora as well as with $A$. madurae; and $A$. spadix is close to $A$. roseoviolacea. However, further comparison of the new species using more isolates, if possible, is required. Pattern differences between species based on single isolates may be unreliable as they cannot take account of the range of variation that may be present in a species.

Similarity values in numerical phenetic surveys can be influenced by differences in growth rates, cultural conditions, test error, lack of test reproducibility, sampling error and by 
Table 3. Distribution of positive characters to the minor clusters and amongst the representatives of the Actinomadura species which were not recovered in major or minor clusters

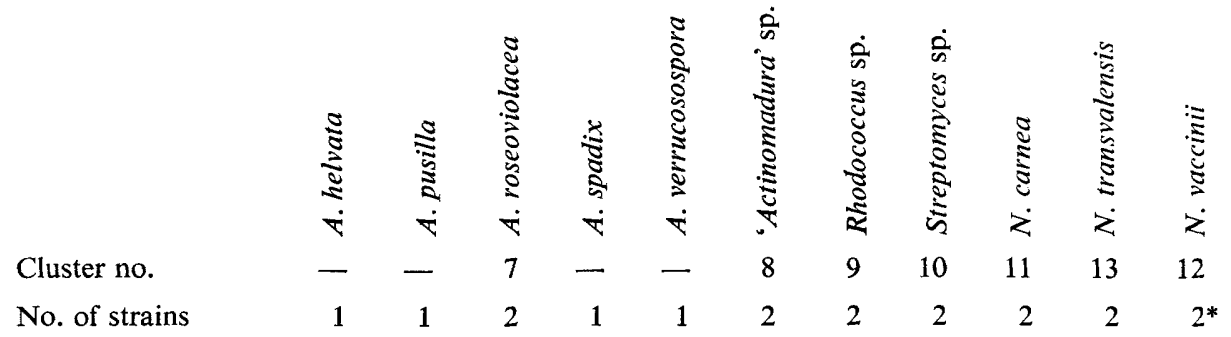

Colonial characters:

Aerial hyphae sparse

Aerial hyphae moderate

$\begin{array}{llll}1 & 1 & 2 & 1 \\ 0 & 1 & 1 & 1 \\ 0 & 0 & 0 & 0 \\ 0 & 0 & 2 & 1 \\ 0 & 1 & 2 & 1 \\ 0 & 1 & 0 & 0 \\ 0 & 0 & 0 & 1 \\ 0 & 1 & 2 & 0 \\ 0 & 0 & 0 & 0 \\ 1 & 0 & 0 & 0 \\ 1 & 0 & 0 & 0 \\ 0 & 0 & 2 & 0 \\ 0 & 0 & 0 & 0 \\ 0 & 1 & 0 & 1\end{array}$

$\begin{array}{llllll}0 & 2 & 2 & 2 & 2 & 2 \\ 0 & 0 & 2 & 2 & 2 & 2 \\ 0 & 0 & 2 & 0 & 2 & 2 \\ 0 & 0 & 0 & 0 & 2 & 2 \\ 1 & 0 & 2 & 2 & 0 & 2 \\ 0 & 0 & 1 & 0 & 0 & 0 \\ 0 & 2 & 1 & 0 & 2 & 0 \\ 2 & 0 & 1 & 0 & 0 & 0 \\ 0 & 0 & 0 & 0 & 0 & 0 \\ 1 & 0 & 0 & 2 & 0 & 2 \\ 0 & 0 & 2 & 0 & 0 & 0 \\ 0 & 0 & 0 & 2 & 0 & 2 \\ 2 & 2 & 0 & 0 & 2 & 0 \\ 0 & 0 & 0 & 0 & 0 & 0\end{array}$

Spines/tufts formed

Margin filamentous

Margin deeply filamentous

Elevation convex

Elevation crateriform

Elevation flat/raised

Elevation irregular

Colonies cream/white

Colonies pink/orange

Colonies red/maroon

Colonies brown

Degradation of:

Adenine
Aesculin
Allantoin
Casein
Chitin
DNA
Elastin
Gelatin
Guanine
Hypoxanthine
Keratin
RNA
Starch
Testosterone
Tween 20
Tween 40
Tween 60
Tween 80
Tyrosine
Urea
Xanthine
Xylan

Growth on sole carbon source $(1 \%, w / v)$ :

$\begin{array}{llllllllllll}\text { Adonitol } & 0 & 1 & 2 & 1 & 1 & 0 & 2 & 2 & 0 & 2 & 0 \\ \text { D-Arabinose } & 0 & 0 & 0 & 0 & 0 & 0 & 0 & 0 & 0 & 2 & 0 \\ \text { L-Arabinose } & 1 & 1 & 2 & 1 & 1 & 2 & 2 & 0 & 0 & 0 & 2 \\ \text { Amygdalin } & 0 & 0 & 0 & 0 & 0 & 0 & 0 & 2 & 0 & 0 & 0 \\ \text { Arbutin } & 0 & 0 & 0 & 0 & 0 & 0 & 2 & 0 & 0 & 0 & 0 \\ \text { Cellobiose } & 1 & 1 & 2 & 1 & 1 & 2 & 1 & 2 & 0 & 0 & 0 \\ \text { Dextrin } & 0 & 1 & 2 & 1 & 1 & 2 & 2 & 2 & 0 & 0 & 2 \\ \text { Dulcitol } & 0 & 0 & 0 & 0 & 0 & 0 & 0 & 0 & 0 & 0 & 0 \\ \text { Erythritol } & 0 & 1 & 0 & 0 & 0 & 0 & 2 & 2 & 0 & 1 & 0 \\ \text { Ethanol } & 0 & 1 & 1 & 0 & 0 & 0 & 0 & 1 & 0 & 2 & 0 \\ \text { Fructose } & 1 & 1 & 2 & 1 & 1 & 2 & 2 & 2 & 0 & 2 & 0 \\ \text { Galactose } & 0 & 1 & 2 & 1 & 1 & 2 & 2 & 2 & 2 & 2 & 2\end{array}$


Table 3 (cont.)

Glucose

Glycerol

Glycogen

Inositol

Inulin

Lactose

Maltose

Mannitol

Mannose

Melezitose

Melibiose

$\alpha$-Methyl-D-glucoside

$\beta$-Methyl-D-glucoside

Raffinose

Rhamnose

Salicin

Sorbitol

Starch

Sucrose

Trehalose

Xylose

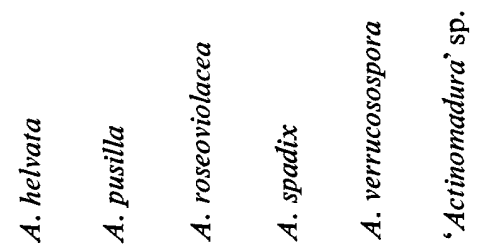

Growth on sole carbon source $(0.1 \%$, w/v):

Glucosamine

$m$-Hydroxybenzoic acid

Sodium acetate

Sodium adipate

Sodium butyrate

Sodium octanoate

Sodium propionate

Sodium tartrate

Testosterone

$$
\begin{array}{lll}
1 & 1 & 2
\end{array}
$$

$\begin{array}{lll}0 & 1 & 2 \\ 0 & 0 & 2\end{array}$

$$
11
$$

$\begin{array}{llll}2 & 2 & 2 & 2\end{array}$

$\begin{array}{lll}0 & 0 & 2 \\ 1 & 0 & 0\end{array}$

$\begin{array}{lll}0 & 1 & 2 \\ 0 & 0 & 2\end{array}$

$\begin{array}{llll}1 & 1 & 2 & 2\end{array}$

$\begin{array}{llll}1 & 1 & 2 & 2\end{array}$

2

00

22

$\begin{array}{llll}0 & 0 & 0 & 2\end{array}$

$\begin{array}{ll}0 & 0 \\ 1 & 0\end{array}$

1

Resistance to: $\dagger$

Demethylchlortetracycline (500) 1

Cephaloridine (100)

Gentamicin (100)

Lincomycin (100)

Neomycin (50)

Oleandomycin (100)

Penicillin (10 i.u.)

Rifampicin (50)

Streptomycin (100)

Tobramycin (50)

Vancomycin (50)

$\begin{array}{ll}0 & 1 \\ 0 & 1 \\ 0 & 1 \\ 0 & 0 \\ 0 & 1 \\ 0 & 0 \\ 0 & 1 \\ 0 & 0 \\ 0 & 0\end{array}$

2
0
2
0
2
0
0
0
0

1
0
1
0
1
0
0
0
0

$\begin{array}{lllllll}0 & 2 & 2 & 0 & 0 & 0 & 0 \\ 0 & 0 & 2 & 0 & 0 & 0 & 0 \\ 0 & 0 & 2 & 2 & 2 & 2 & 0 \\ 0 & 0 & 0 & 0 & 0 & 2 & 0 \\ 1 & 0 & 2 & 2 & 2 & 2 & 0 \\ 1 & 0 & 0 & 0 & 0 & 2 & 0 \\ 1 & 2 & 2 & 2 & 2 & 2 & 2 \\ 0 & 0 & 0 & 0 & 0 & 0 & 0 \\ 0 & 0 & 0 & 0 & 2 & 2 & 0\end{array}$

Resistance to:

Lysozyme

1
0
0
0
0
0
1
0
1
0
1

$\begin{array}{llll}\mathbf{0} & 1 & \mathbf{1} & \mathbf{0} \\ 0 & 0 & \mathbf{0} & 0 \\ 0 & 0 & 1 & 0 \\ 0 & 0 & 0 & 0 \\ 0 & 0 & 1 & 1 \\ 0 & 0 & 0 & 0 \\ 0 & 0 & 0 & 0 \\ 0 & 0 & 0 & 0 \\ 0 & 0 & 1 & 0 \\ 1 & 1 & 1 & 0 \\ 0 & 0 & 1 & 0\end{array}$

$\begin{array}{llllll}2 & 2 & 2 & 0 & 0 & 0 \\ 0 & 0 & 0 & 2 & 0 & 0 \\ 2 & 2 & 2 & 2 & 0 & 2 \\ 0 & 2 & 0 & 0 & 0 & 0 \\ 2 & 2 & 2 & 2 & 0 & 2 \\ 0 & 0 & 0 & 0 & 0 & 0 \\ 2 & 2 & 0 & 1 & 0 & 0 \\ 0 & 2 & 0 & 0 & 0 & 0 \\ 2 & 2 & 2 & 2 & 0 & 2 \\ 0 & 2 & 2 & 2 & 0 & 2 \\ 2 & 2 & 2 & 2 & 0 & 0\end{array}$

* Nocardia salmonicida omitted.

$\uparrow$ See Table 2. 


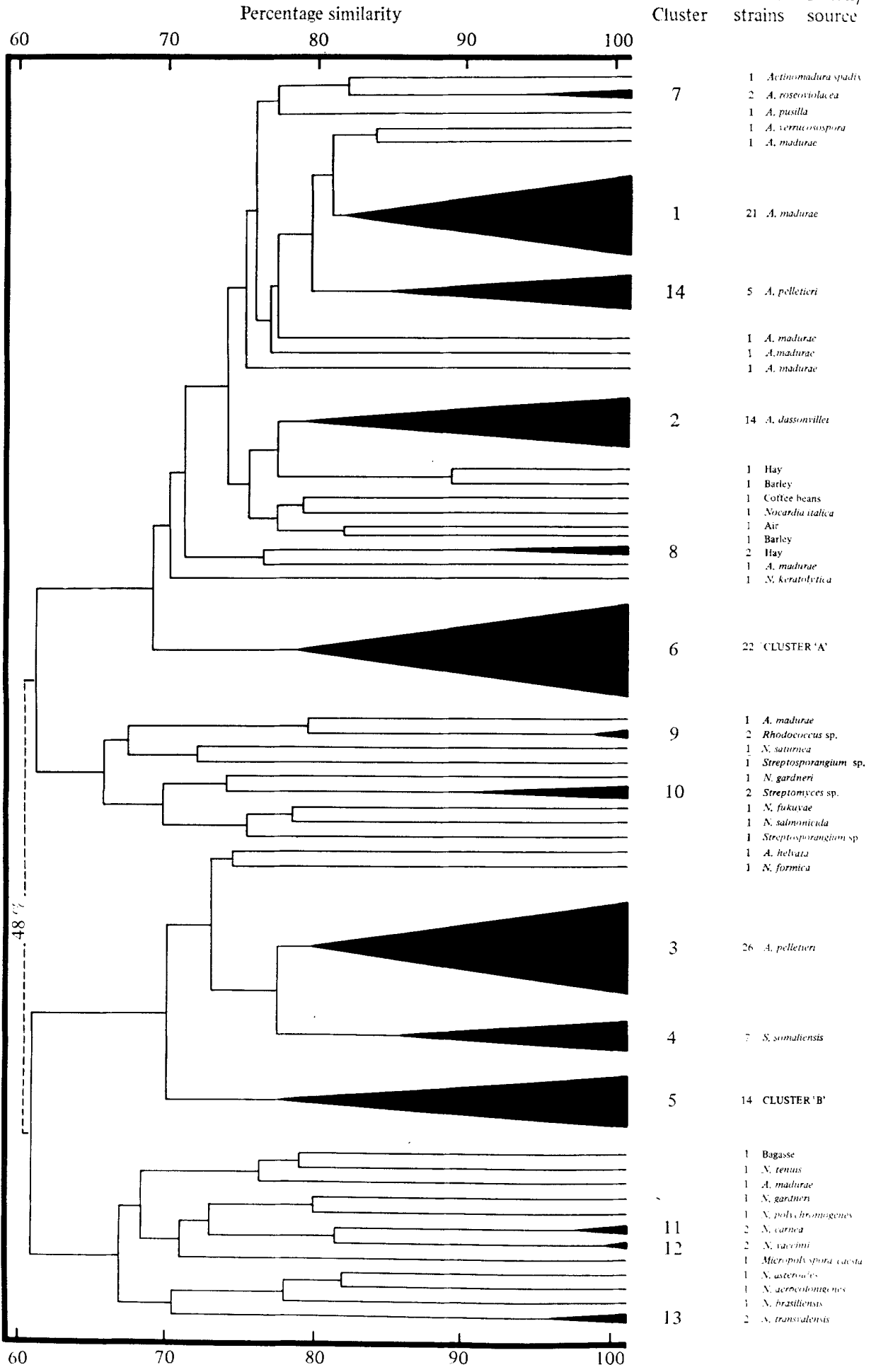

Fig. 2. A simplified dendrogram showing the relationships between clusters based on the $S_{S M}$ coefficient and unweighted average linkage clustering (UPGMA). 


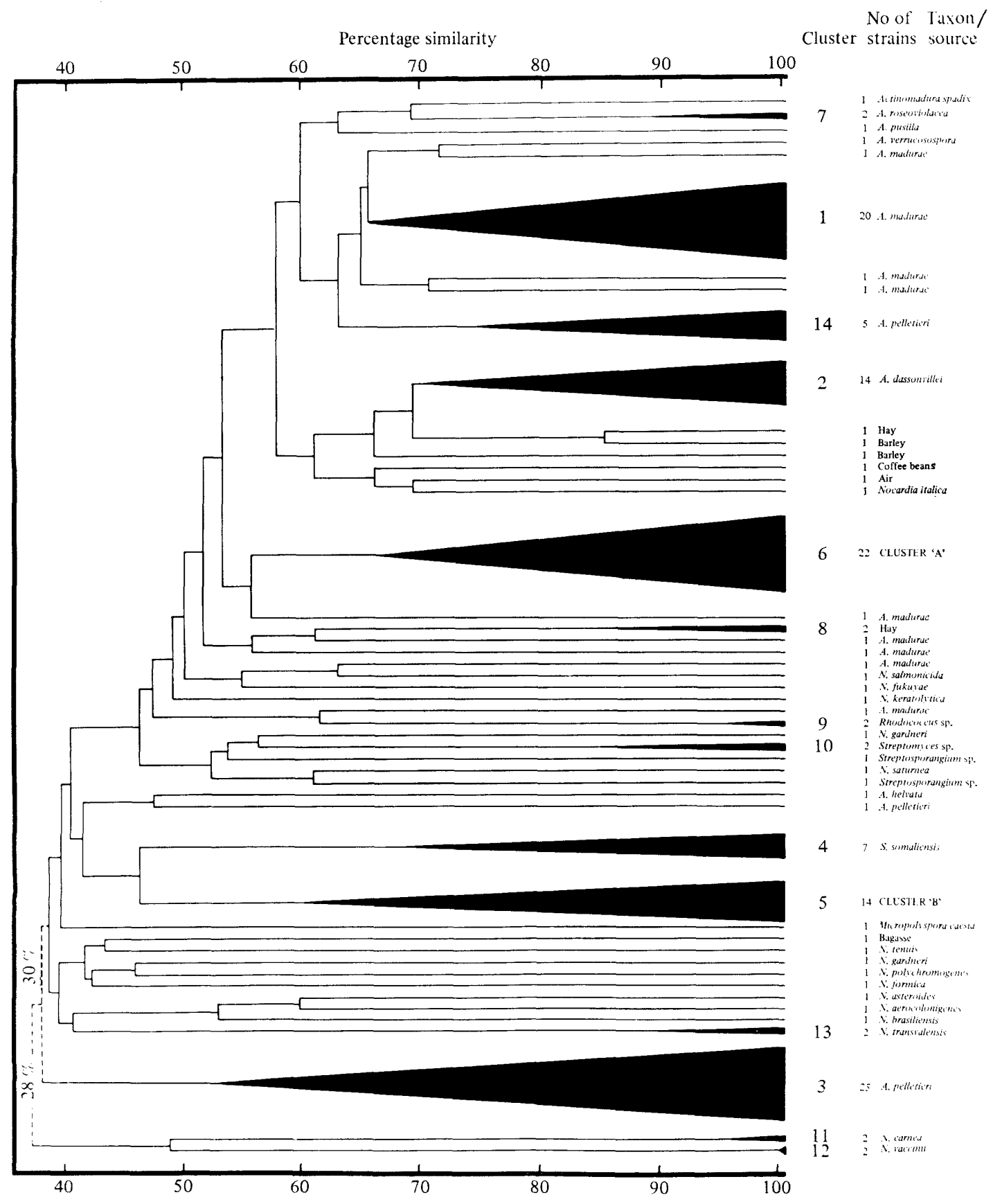

Fig. 3. A simplified dendrogram showing the relationships between clusters based on the $S_{J}$ coefficient and unweighted average linkage clustering (UPGMA). 
Table 4. Distinguishing characters for Actinomadura species and allied taxa

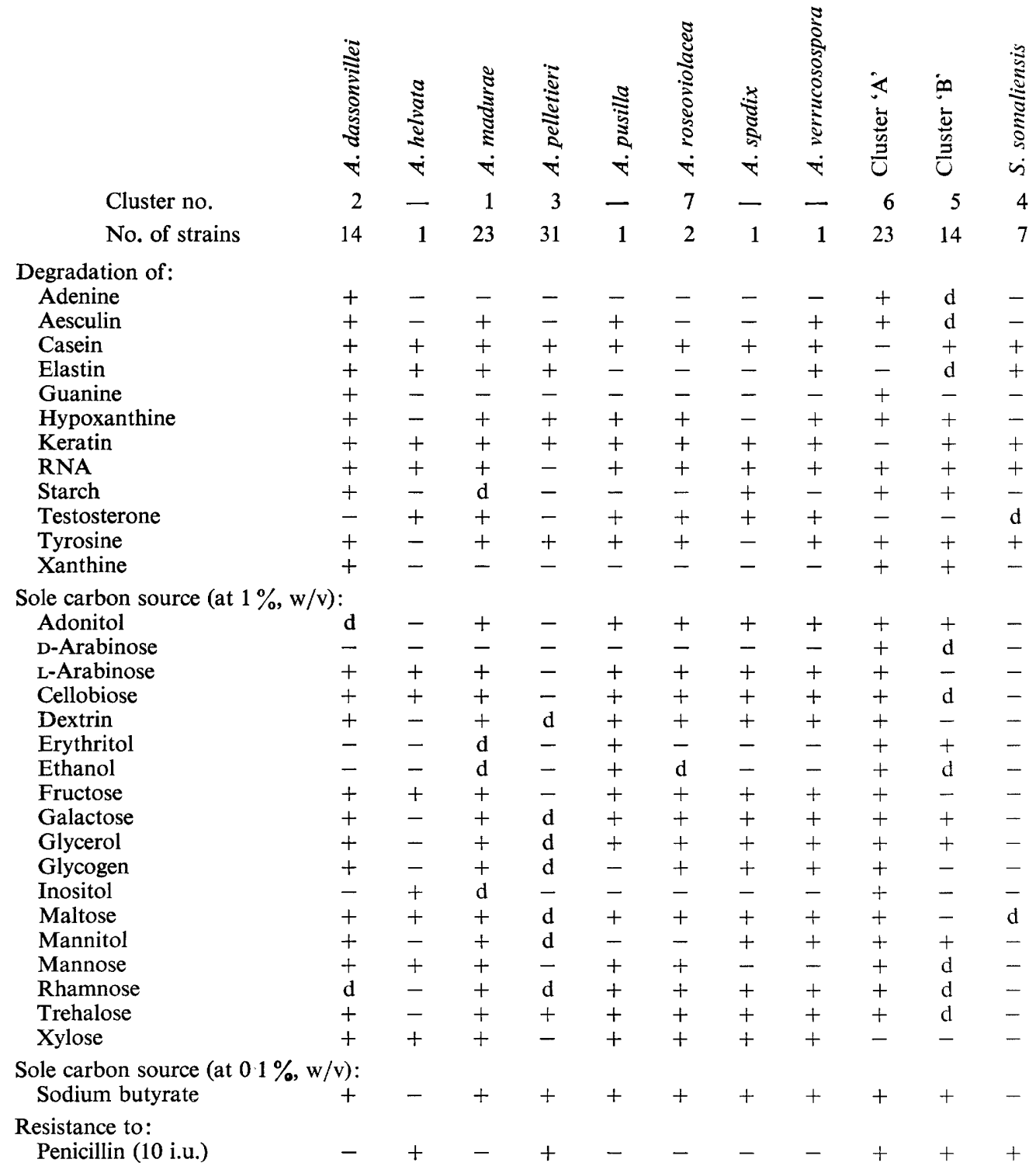

+ , More than $85 \%$ of strains positive; - , more than $85 \%$ of strains negative; d, strains 16 to $84 \%$ positive.

the coefficients and clustering algorithms employed (Sneath, 1968; Sneath \& Johnson, 1972; Austin \& Colwell, 1977; Goodfellow, 1977). Thus, the unexpectedly large similarities reported between A. pelletieri and Nocardia sensu stricto (Holmberg \& Hallander, 1973), between Actinomadura and S. somaliensis (Kurup \& Schmitt, 1973) and between A. pelletieri and Rothia dentocariosa (Jones, 1975) can probably be accounted for by such factors. Such spurious similarities and dissimilarities can be detected by evaluating numerical data with different coefficients of association and clustering algorithms and comparing results with classification based on other types of data, e.g. chemical, genetical and morphological (Goodfellow et al., 1978). 
Many different coefficients have been used successfully in numerical taxonomic studies of bacteria, but their choice tends to be subjective and comparisons are few (Austin \& Colwell 1977). The significance of negative matches and possible distortions due to growth rate must be taken into account. The Jaccard coefficient $\left(S_{J}\right.$; Sneath, 1957) excludes negative matches, thus emphasizing differences between strains with few positive characters in common. Many of our strains showed few positive characters and differed markedly in growth rate. For this reason, data were analysed using $S_{S M}$ and $D_{P}$ coefficients as well as $S_{J}$. The use of different clustering methods does not affect the formation of clusters where these are homogeneous and there are no intermediates. However, where there are intermediates, average linkage gives much more compact clusters than single linkage.

Our classification has been primarily based on pattern differences although cluster composition was not markedly affected either by the coefficients or clustering algorithms used or by the $4.5 \%$ test error. However, the coefficients of association used did affect the relationships between the major clusters while the similarity between $A$. pelletieri and $S$. somaliensis in $S_{S M}$ analyses owed much to negative correlation (Figs 1, 2 and 3). These numerical findings are difficult to interpret. While the major clusters, with the exception of cluster 14, can be considered to represent good taxospecies, little can be said about the grouping of these species into genera. At present there is no objective way of equating similarity values with orthodox taxonomic rank, but numerical data can be interpreted in the light of results collected using independent taxonomic criteria.

Chemical characters have been particularly useful in evaluating numerical phenetic classifications (Lechevalier \& Lechevalier, 1970; Lacey \& Goodfellow, 1975; Goodfellow \& Minnikin, 1978). Thus, $S$. somaliensis, like other streptomycetes, has a wall chemotype I (Becker et al., 1965; Pridham \& Lyons, 1969) and can thereby be distinguished from Actinomadura with a type III wall. These two taxa can also be distinguished by polar lipid composition (Lechevalier et al., 1977), isoprenoid quinone content (Collins et al., 1977) and data from serological analyses (González-Ochoa \& Vásquez-Hoyos, 1953; Schneidau \& Shaffer, 1957). The chemical and serological data in conjunction with the numerical data from the $S_{J}$ analysis provide good grounds for continuing to classify $S$. somaliensis and $A$. pelletieri strains in separate genera.

Although the strains in clusters ' $\mathrm{A}$ ' and ' $\mathrm{B}$ ' have a morphology resembling Actinomadura, they showed little similarity with the phena representing the original three species of this genus. The sole exceptions (A74 and A107) within cluster 1 (A. madurae) were, in fact, removed from this cluster by $S_{J}$ and $S_{S M}$ analyses. These strains were isolated from hay and the air of a barley silo, respectively, and may be misplaced from cluster 6 (cluster ' $A$ '). Clusters ' $A$ ' and ' $B$ ' were also clearly distinguished from the Nocardia clusters and from the type strains of $N$. asteroides and $N$. brasiliensis. Preliminary chemical data support the separation of clusters 'A' and 'B' strains from both Nocardia and Actinomadura. Representative strains of these taxa contain meso-diaminopimelic acid, arabinose and galactose (G. H. Bowden, personal communication) but, unlike nocardiae, do not contain mycolic acids. The relationships of the isolates provisionally classified in clusters ' $A$ ' and ' $B$ ' are in need of systematic study with actinomycetes having similar chemical and morphological features. Chemical criteria should not necessarily outweigh other taxonomic criteria although they have helped improve the classification of actinomycetes (Lechevalier et al., 1977; Goodfellow \& Minnikin, 1978).

The new genus Nocardiopsis has been proposed for isolates previously classified as $A$. dassonvillei (Meyer, 1976). This proposal has much to commend it, as $A$. dassonvillei differs from $A$. madurae and $A$. pelletieri in many characteristics (Lacey et al., 1978), but our study raises some doubts about its advisability at present. While cluster 2 ( $A$. dassonville $i)$ shares little similarity with clusters 1 ( $A$. madurae) and 3 (A. pelletieri) the latter are even more sharply distinguished. Tsukamura (1969) also found little similarity between $A$. madurae and $A$. pelletieri strains. Since $A$. madurae and $A$. pelletieri show many chemical 
similarities, further systematic studies are required to establish the degree of their relationship.

Two ways of treating the genus Actinomadura as constituted by Lechevalier \& Lechevalier (1970) thus seem possible at present. Either the original concept can be retained or the removal of $A$. dassonvillei to Nocardiopsis can be accepted. In the latter case there would be equal justification on phenetic grounds for creating a new genus for strains of $A$. pelletieri and possibly dividing it into two species. Given the difficulties associated with the classification of Actinomadura and the lack of systematic studies of the newly described species, the more cautious alternative seems preferable at present.

The authors are indebted to colleagues who kindly provided cultures (see Table 1), to Dr J. R. Leece for help with the computation and to Mr G. H. Bowden for information on wall composition. This investigation was supported by Medical Research Council grant G974/522/s.

\section{REFERENCES}

Agre, N. S., Efimova, T. P. \& Guzeva, L. N. (1975). Heterogeneity of the genus Actinomadura Lechevalier and Lechevalier. Microbiologiya 44, 252-257.

Austin, B. \& Colwell, R. R. (1977). Evaluation of some coefficients for use in numerical taxonomy of micro-organisms. International Journal of Systematic Bacteriology 27, 204-210.

BeCker, B., Lechevalier, M. P. \& Lechevalier, H. A. (1965). Chemical composition of cell-wall preparations from strains of various form-genera of aerobic actinomycetes. Applied Microbiology 13, 236-243.

BrocQ-Rousseu, M. D. (1904). Sur un Streptothrix cause de l'altération des avoines moisies. Revue générale de botanique 16, 219-230.

Collins, M. D., Pirouz, T., Goodfellow, M. \& Minnikin, D. E. (1977). Distribution of menaquinones in actinomycetes and corynebacteria. Journal of General Microbiology 100, 221230.

Cross, T. \& Goodfellow, M. (1973). Taxonomy and classification of the actinomycetes. In Actinomycetales: Characteristics and Practical Importance, pp. 11-112. Edited by G. Sykes \& F. A. Skinner. London: Academic Press.

González-OchoA, A. \& VásQuez-Hoyos, A. (1953). Relationes serogiaes de los principales actinomycetes patogens. Revista del Instituto de salubridady enfermedades tropicales, Mexico 13, 177-187.

Goodfellow, M. (1971). Numerical taxonomy of some nocardioform bacteria. Journal of General Microbiology 69, 33-80.

Goodfellow, M. (1977). Numerical taxonomy. In CRC Handbook of Microbiology, 2nd edn, vol. 1. Bacteria, pp. 579-596. Edited by A. I. Laskin \& H. A. Lechevalier. Ohio: CRC Press.

Goodfellow, M. \& Alderson, G. (1977). The actinomycete-genus Rhodococcus: a home for the 'rhodochrous' complex. Journal of General Microbiology 100, 99-122.

Goodfellow, M. \& MinNikin, D. E. (1978). Numerical and chemical methods in the classification of Nocardia and related taxa. Zentralblatt für Bakteriologie, Parasitenkunde, Infektionskranheiten und Hygiene (Abteilung I), Supplement 6, 43-51.
Goodfellow, M. \& ORCHARD, V. A. (1974). Antibiotic sensitivity of some nocardioform bacteria and its value as a criterion for taxonomy. Journal of General Microbiology 83, 375-387.

Goodfellow, M., Lind, A., Mordarska, H., PatTyn, S. \& Tsukamura, M. (1974). A cooperative numerical analysis of cultures considered to belong to the 'rhodochrous' taxon. Journal of General Microbiology 85, 291-302.

Goodfellow, M., Orlean, P. A. B., Collins, M. D. \& Alshamaony, L. (1978). Chemical and numerical taxonomy of strains received as Gordona aurantiaca. Journal of General Microbiology 109, 57-68.

Gordon, R. E. (1966). Some criteria for the recognition of Nocardia madurae (Vincent) Blanchard. Journal of General Microbiology 45, 355-364.

GoRDON, R. E. (1967). The taxonomy of soil bacteria. In The Ecology of Soil Bacteria, pp. 293 321. Edited by T. R. G. Gray \& D. Parkinson. Liverpool: Liverpool University Press.

Gordon, R. E. \& Horan, A. C. (1968). Nocardia dassonvillei, a replica of Streptomyces griseus. Journal of General Microbiology 50, 235-240.

Gordon, R. E. \& MiHM, J. M. (1962). Identification of Nocardia caviae (Erikson) nov. comb. Annals of the New York Academy of Sciences 98, 628-636.

Gregory, P. H. \& LACEY, M. E. (1963). Mycological examination of dust from mouldy hay associated with farmer's lung disease. Journal of General Microbiology 30, 75-88.

Holmberg, K. \& Hallander, H. O. (1973). Numerical taxonomy and laboratory identification of Bacterionema matruchotii, Rothia dentocariosa, Actinomyces naeslundii, Actinomyces viscosus, and some related bacteria. Journal of General Microbiology 76, 43-63.

Jefrries, C. D., Holtman, D. F. \& Guse, D. G. (1957). Rapid method for determining the activity of micro-organisms on nucleic acids. Journal of Bacteriology 73, 590-591.

JONES, D. (1975). A numerical taxonomic study of coryneform and related bacteria. Journal of General Microbiology 87, 52-96.

Kurup, P. V. \& SchmitT, J. A. (1973). Numerical taxonomy of Nocardia. Canadian Journal of Microbiology 19, 1035-1048. 
LACEY, J. (1971). The microbiology of moist barley storage in unsealed silos. Annals of Applied Biology 69, 187-212.

LACEY, J. (1974). Moulding of sugar-cane bagasse and its prevention. Annals of Applied Biology 76, 63-67.

LACEY, J. (1978). Ecology of actinomycetes in fodders and related substrates. Zentralblatt für Bakteriologie, Parasitenkunde, Infektionskrankheiten und Hygiene (Abteilung I), Supplement 6, 161-170.

LACEy, J. \& Goodfellow, M. (1975). A novel actinomycete from sugar-cane bagasse: Saccharopolyspora hirsuta gen. et $\mathrm{sp}$. nov. Journal of General Microbiology 88, 75-85.

LaCey, J., Goodfellow, M. \& Alderson, G. (1978). The genus Actinomadura Lechevalier and Lechevalier. Zentralblatt für Bakteriologie, Parasitenkunde, Infektionskrankheiten und Hygiene (Abteilung I), Supplement 6, 107-117.

Lavrova, N. V., Preobrazhenskaya, T. P. \& SVESHNikova, M. A. (1972). Isolation of actinomycetes on selective media with rubomycin. Antibiotiki 17, 965-970.

Lechevalier, M. P. \& Gerber, N. N. (1970). The identity of madurose with 3-O-methyl-D-galactose. Carbohydrate Research 13, 451-454.

Lechevalier, H. A. \& Lechevalier, M. P. (1970). A critical evaluation of the genera of aerobic actinomycetes. In The Actinomycetales, pp. 393405. Edited by H. Prauser. Jena: Gustav Fischer Verlag.

Lechevalier, H. A., Lechevalier, M. P. \& Gerber, N. N. (1971). Chemical composition as a criterion in the classification of actinomycetes. Advances in Applied Microbiology 14, 47-72.

Lechevalier, M. P., De Bievre, C. \& Lechevalier, H. (1977). Chemotaxonomy of aerobic actinomycetes: phospholipid composition. Biochemical Systematics and Ecology 5, 249-260.

McClung, N. M. (1974). Nocardiaceae Castellani and Chalmers 1919. In Bergey's Manual of Determinative Bacteriology, 8th edn, pp. 726-746. Edited by R. E. Buchanan \& N. E. Gibbons. Baltimore: Williams \& Wilkins.

MEYER, J. (1976). Nocardiopsis, a new genus of the order Actinomycetales. International Journal of Systematic Bacteriology 26, 487-493.

Minnikin, D. E., Alshamaony, L. \& Goodfellow, M. (1975). Differentiation of Mycobacterium, Nocardia and related taxa by thin-layer chromatographic analysis of whole-organism methanolysates. Journal of General Microbiology 88, 200-204.

Minnikin, D. E., Pirouz, T. \& Goodfellow, M. (1977). Polar lipid composition in the classification of some Actinomadura species. International Journal of Systematic Bacteriology 27, 118-121.

Mordarski, M., Goodfellow, M., Szyba, K., Pulverer, G. \& Tkacz, A. (1977). Classification of the 'rhodochrous' complex and allied taxa based upon deoxyribonucleic acid reassociation. International Journal of Systematic Bacteriology 27, 31-37.

Nonomura, H. \& OHARA, Y. (1971). Distribution of actinomycetes in soil. XI. Some new species of the genus Actinomadura Lechevalier et al. Journal of Fermentation Technology 49, 904-912.

Prauser, H. (1976). Host-phage relationships in nocardioform organisms. In The Biology of the Nocardiae, pp. 266-284. Edited by M. Goodfellow, G. H. Brownell \& J. A. Serrano. London: Academic Press.

Pridham, T. G. \& Lyons, A. J., JR. (1969). Progress in classification of the taxonomic and nomenclatural status of some problem actinomycetes. Developments in Industrial Microbiology 10, 183-221.

SchaAl, K. P. (1977). Nocardia, Actinomadura and Streptomyces. In CRC Handbook Series in Clinical Laboratory Sciences, Section E, Clinical Microbiology, vol. 1, pp. 131-144. Edited by A. von Graevenitz. Ohio: CRC Press.

Schneidau, J. D., JR \& Shaffer, M. F. (1957). Studies on Nocardia and other Actinomycetales. Annual Review of Tuberculosis 76, 770-788.

SNeATH, P. H. A. (1957). The application of computers to taxonomy. Journal of General Microbiology 17, 201-226.

Sneath, P. H. A. (1968). Vigour and pattern in taxonomy. Journal of General Microbiology 54, $1-11$.

Sneath, P. H. A. \& Johnson, R. (1972). The influence on numerical taxonomic similarities of errors in microbiological tests. Journal of General Microbiology 72, 377-392.

Sneath, P. H. A. \& Sokal, R. R. (1974). Numerical Taxonomy. The Principles and Practice of Numerical Classification. San Francisco: W. H. Freeman.

Sneath, P. H. A. \& Stevens, M. (1967). A divided petri dish for use with multipoint inoculators. Journal of Applied Bacteriology 30, 495-497.

SoKAL, R. R. \& MicheNER, C. D. (1958). A statistical method for evaluating systematic relationships. Kansas University Science Bulletin 38, 1409-1438.

Tsukamura, M. (1969). Numerical taxonomy of the genus Nocardia. Journal of General Microbiology 56, 265-287.

WishaRT, D. (1968). A Fortran II Program for Numerical Taxonomy. St Andrews: University of St Andrews.

Williams, S. T., Sharples, G. P., Serrano, J. A., Serrano, A. A. \& Lacey, J. (1976). The micromorphology and fine structure of nocardioform organisms. In The Biology of the Nocardiae, pp. 102-140. Edited by M. Goodfellow, G. H. Brownell \& J. A. Serrano. London: Academic Press. 